\title{
Beer à no-go: Learning to stop responding to alcohol cues reduces alcohol intake via reduced affective associations rather than increased response inhibition
}

Citation for published version (APA):

Houben, K., Havermans, R. C., Nederkoorn, C., \& Jansen, A. (2012). Beer à no-go: Learning to stop responding to alcohol cues reduces alcohol intake via reduced affective associations rather than increased response inhibition. Addiction, 107(7), 1280-1287. https://doi.org/10.1111/j.13600443.2012.03827.x

Document status and date:

Published: 01/07/2012

DOI:

10.1111/j.1360-0443.2012.03827.x

Document Version:

Publisher's PDF, also known as Version of record

Document license:

Taverne

Please check the document version of this publication:

- A submitted manuscript is the version of the article upon submission and before peer-review. There can be important differences between the submitted version and the official published version of record.

People interested in the research are advised to contact the author for the final version of the publication, or visit the DOI to the publisher's website.

- The final author version and the galley proof are versions of the publication after peer review.

- The final published version features the final layout of the paper including the volume, issue and page numbers.

Link to publication

\footnotetext{
General rights rights.

- You may freely distribute the URL identifying the publication in the public portal. please follow below link for the End User Agreement:

www.umlib.nl/taverne-license

Take down policy

If you believe that this document breaches copyright please contact us at:

repository@maastrichtuniversity.nl

providing details and we will investigate your claim.
}

Copyright and moral rights for the publications made accessible in the public portal are retained by the authors and/or other copyright owners and it is a condition of accessing publications that users recognise and abide by the legal requirements associated with these

- Users may download and print one copy of any publication from the public portal for the purpose of private study or research.

- You may not further distribute the material or use it for any profit-making activity or commercial gain

If the publication is distributed under the terms of Article $25 \mathrm{fa}$ of the Dutch Copyright Act, indicated by the "Taverne" license above, 


\title{
Beer à no-go: learning to stop responding to alcohol cues reduces alcohol intake via reduced affective associations rather than increased response inhibition
}

\author{
Katrijn Houben, Remco C. Havermans, Chantal Nederkoorn \& Anita Jansen \\ Clinical Psychological Science, Maastricht University, Maastricht, the Netherlands
}

\begin{abstract}
Aims Previous research has shown that consistently not responding to alcohol-related stimuli in a go/no-go training procedure reduces drinking behaviour. This study aimed to examine further the mechanisms underlying this go/no-go training effect. Design, setting and participants Fifty-seven heavy drinkers were assigned randomly to two training conditions: in the beer/no-go condition, alcohol-related stimuli were always paired with a stopping response, while in the beer/go condition participants always responded to alcohol-related stimuli. Participants were tested individually in a laboratory at Maastricht University. Measurements Weekly alcohol intake, implicit attitudes towards beer, approach-avoidance action tendencies towards beer and response inhibition were measured before and after the training. Findings Results showed a significant reduction in both implicit attitudes $(P=0.03)$ and alcohol intake $(P=0.02)$ in the beer/no-go condition, but not in the beer/go condition. There were no significant training effects on action tendencies or response inhibition. Conclusions Repeatedly stopping pre-potent responses towards alcoholrelated stimuli reduces excessive alcohol use via a devaluation of alcohol-related stimuli rather than via increased inhibitory control over alcohol-related responses.
\end{abstract}

Keywords Alcohol, go/no-go task, implicit attitudes, response inhibition.

Correspondence to: Katrijn Houben, Clinical Psychological Science, Maastricht University, PO Box 616, 6200 MD Maastricht, the Netherlands.

E-mail: k.houben@maastrichtuniversity.nl

Submitted 22 September 2011; initial review completed 21 November 2011; final version accepted 24 January 2012

\section{INTRODUCTION}

Addictive behaviours such as alcohol abuse involve a conflict between the hedonic impulse to drink alcohol and the intention to refrain from acting on this impulse. Dualsystem models explain such conflicts by postulating that two distinct cognitive processes guide drinking behaviour [1-3]: a fast impulsive (automatic or implicit) system, which directs drinking behaviour via automatic affective associations, and a slow reflective (controlled or explicit) system that guides behaviour through deliberate decisions. Importantly, the reflective system can override impulsive responses if one has enough cognitive resources for effortful cognitive control. Thus, drinking behaviour is instigated by impulsive processes, unless one is able to engage in controlled processing to regulate such impulses. In line with this model, stronger positive implicit attitudes towards alcohol (impulsive system) predict increased alcohol consumption [4-8], especially when cognitive control abilities, such as response inhibition and working memory, are reduced [9-11].

Importantly, these insights suggest two possible routes to behavioural change: first, interventions could target automatic affective processes that guide alcohol use. For instance, decreasing implicit attitudes towards alcohol via evaluative conditioning procedures has been demonstrated to reduce alcohol intake effectively $[12,13]$. Secondly, interventions could also increase cognitive control abilities, such as response inhibition and working memory, so that automatic impulses to drink alcohol can be regulated more easily. Consistent with this idea, we showed that increasing working memory capacity decreases alcohol intake, especially for people who experience strong impulses to drink alcohol [14]. Thus, both routes to changing drinking behaviour appear to have merit. 
Further, we have also shown that drinking behaviour can be reduced via a go/no-go training procedure [15]. Specifically, repeatedly withholding responses to alcoholrelated stimuli caused implicit attitudes towards alcohol to become more negative, and reduced drinking behaviour. However, the mechanisms underlying the observed change in drinking behaviour still remain unclear. According to the Behavior Stimulus Interaction (BSI) theory proposed by Veling et al. [16], positive stimuli automatically elicit approach tendencies due to their reward value. Consequently, pairing such rewarding stimuli with situational cues signalling that approach is unwanted (i.e. a no-go signal) causes a response conflict $[16,17]$. This response conflict is then resolved via a devaluation of the stimuli that were paired consistently with stopping [16], and by reducing approach tendencies towards these stimuli [17]. Further, Verbruggen \& Logan demonstrated that mapping stimuli consistently onto a stopping response can increase response inhibition effectively for those stimuli [18].

Thus, the change in drinking behaviour that resulted from the go/no-go training could have been caused via three different mechanisms: first, alcohol-related stimuli may have been devalued, thereby decreasing automatic impulses to drink alcohol that reside in the impulsive system. Indeed, in line with this idea, the change in drinking behaviour coincided with a change in implicit attitudes [15]. Secondly, this devaluation of alcoholrelated stimuli may have also reduced the automatic motivation to approach alcohol that is activated typically by the impulsive system in response to the rewarding value of alcohol stimuli. Thirdly, repeatedly stopping responses to alcohol stimuli may have increased the ability of the reflective system to inhibit impulsive responses to alcohol stimuli, thereby increasing inhibitory control over drinking behaviour. Importantly, these mechanisms are not mutually exclusive and may have contributed jointly to the observed behavioural change.

The aim of this study was to replicate our previous findings with go/no-go training, and to explore via which mechanism(s) pairing alcohol-related stimuli with a stopping response reduces drinking behaviour. It was hypothesized that withholding responses to alcohol stimuli during the training would cause (i) a devaluation of alcohol-related stimuli; (ii) a change in action tendencies to approach or avoid alcohol-related stimuli; and (iii) improve response inhibition for alcohol-related stimuli. Finally, we examined which of these (changed) processes contributed to the expected behavioural change in drinking.

\section{METHOD}

\section{Participants}

Participants were 57 heavy drinking Maastricht University students [24 female students; mean age $=20.91$, standard deviation $(\mathrm{SD})=1.83]$. Participants were included only if they consumed on average 12 (males) or 10 (females) alcoholic consumptions or more per week and if beer was their preferred alcoholic beverage. On average, participants consumed 23.29 (SD = 11.92) Dutch standard drinking units of $10 \mathrm{~g}$ of alcohol per week. On the Alcohol Use Disorder Identification Test (AUDIT [19]), participants had an average score of 13.97 $(\mathrm{SD}=2.47)$.

\section{Materials and measures}

\section{Go/no-go task}

During the go/no-go task, four pictures of glasses of beer and four pictures of empty glasses were presented. Participants were instructed to press the space bar when a go cue was displayed, and to withhold responding when a no-go cue was shown. The go/no-go cues were the letters 'p' and 'f' (with counterbalanced instructions), displayed randomly in one of four corners of the pictures. In the beer/no-go condition, beer-related pictures were paired consistently with the no-go cue, while pictures of empty glasses were paired consistently with the go cue. In the beer/go condition, beer-related pictures were always paired with the go cue, and pictures of empty glasses were always paired with the no-go cue. ${ }^{\dagger}$

The go/no-go task consisted of two blocks of 160 trials. Trials were presented randomly, but go or no-go trials were never presented more than four consecutive times. During each trial, picture and cue were presented together (1500 ms). A green circle was displayed after a correct (non)response (500 ms), and a red cross after an incorrect (non)response (500 ms).

\footnotetext{
tThe reason for including this beer/go condition was twofold: first, previous research showed that pairing stimuli repeatedly with no-go cues caused a devaluation of those stimuli, while pairing stimuli consistently with go cues did not change stimulus evaluations [16]. For ease of comparison across studies $[15,16]$, we decided to use the same two conditions in the present research. Secondly, the beer/go condition was deemed to be a more appropriate control condition for the beer/no-go condition compared to a control condition where participants, for instance, would respond to alcohol on $50 \%$ of the trails and withhold responding on the other $50 \%$ of the trails. Such a control condition may not rule out training effects completely, similar to those in the beer/no-go condition. Nevertheless, future research should examine the value of such alternative control conditions that do not involve responding consistently to alcohol cues to avoid inadvertently increasing impulsive drinking behaviour.
} 
Implicit Association Test (IAT)

As in our previous study [15], implicit attitudes towards beer were measured with the IAT, a computerized classification task based on the assumption that it is easier to classify two concepts that are associated using the same response than to classify unassociated concepts with the same response [20]. Participants had to classify stimuli into two target categories (i.e. beer and empty glasses) and two affective attribute categories (i.e. positive and negative). The 'beer' and 'empty' target categories each consisted of six pictures (including the pictures presented during the go/no-go task). The attribute categories were 'pleasant' (happy, jolly, energetic, funny, sociable, cheerful) and 'unpleasant' (dull, miserable, sick, depressed, unhappy, drowsy).

The IAT consisted of seven blocks. In blocks 1 and 2, participants practised the target categorization and the attribute categorization, respectively, using two response keys (24 trials). In blocks 3 (practice; 24 trials) and 4 (test; 48 trials), participants classified stimuli from one target and one attribute category (e.g. beer and pleasant) with one response key, and stimuli belonging to the other two categories (e.g. empty and unpleasant) with the other response key. In block 5 (48 trials), participants practised the reversed target classification. In blocks 6 (practice; 24 trials) and 7 (test; 48 trials), participants performed the reverse combination of targets and attributes (e.g. beer and unpleasant versus empty and pleasant). The response assignment of the attribute categories and the order of the combined sorting conditions (blocks 3 and 4 and blocks 6 and 7) were counterbalanced.

IAT effects were calculated with the D600 algorithm [21]: mean reaction times (RT) were calculated separately for the two combination tasks, including both practice (blocks 3 and 6) and test blocks (blocks 4 and 7). IAT scores were calculated as the difference between these two RTs so that higher IAT scores indicate faster performance when beer was paired with pleasant than when beer was paired with unpleasant. Further, following the formula presented by Greenwald et al. [21], error penalties (600 ms) were given, and scores were standardized for each participant.

\section{Stimulus response compatibility (SRC) task}

Approach-avoidance action tendencies were assessed with the SRC task, which is based on the supposition that one is faster to approach liked stimuli and avoid disliked stimuli than to approach disliked stimuli and avoid liked stimuli [22]. During this task, four beer-related pictures and four pictures of empty glasses were presented (the same pictures as used during the go/no-go task), as well as eight filler pictures (e.g. a wooden shoe, a traffic cone, a cardboard box). Pictures were displayed in the centre of the computer screen together with a manikin (a matchstick figure) placed exactly between the outer border of the picture and the edge of the screen.

The SRC task comprised two blocks of 32 trials (counterbalanced): in one block, participants had to approach drinking-related pictures (i.e. beer-related pictures and pictures of empty glasses) and avoid filler pictures by moving the manikin towards or away from the picture using the up- and down-arrow keys. In the other block, participants had to avoid drinking-related pictures and approach filler pictures. Approach and avoidance tendencies for beer were calculated as the mean RT separately for trials that involved approaching beer-related stimuli, and trials that involved avoiding beer-related pictures. Mean approach and avoidance RTs for pictures of empty glasses were calculated in the same fashion.

\section{Stop-signal task (SST)}

To measure response inhibition we used the SST, which is based on the notion that response inhibition can be operationalized as the ability to inhibit pre-potent responses, and which involves deliberately stopping a prepared motor response when a stop signal is presented [23]. During the SST, four beer-related pictures and four pictures of empty glasses (the same pictures as presented during the go/no-go task) were presented. Upon presentation of a picture (i.e. the go signal), participants had to indicate as quickly as possible whether the glass in the picture was full or empty by pressing one of two response keys. However, when an auditory stop signal was presented, this response had to be inhibited $(25 \%$ of the trials). The stop signal was presented at random intervals (i.e. stop delay) either $100 \mathrm{~ms}, 200 \mathrm{~ms}, 300 \mathrm{~ms}$ or $400 \mathrm{~ms}$ after the go signal.

The SST comprised seven blocks. Participants first completed two practice blocks without stop signals and one practice block with stop signals. Afterwards, they completed four test blocks of 64 trials. The main dependent variable in the SST is stop-signal reaction time (SSRT), with higher SSRTs reflecting less efficient response inhibition. We calculated SSRT for beer-related trials as follows [24]: first, all RTs on the beer-go trials of a participant were rank-ordered, from fastest to slowest. Secondly, the $n$th percentage RT was picked, $n$ being defined by the probability of responding given a stop signal. Thirdly, the average stop delay was subtracted from this RT to estimate SSRT. SSRTs for trials with pictures of empty glasses were calculated in the same manner.

\section{Alcohol use}

Weekly alcohol consumption was measured using the time-line follow-back questionnaire (TLFB) [25,26]. 
Participants indicated how many alcoholic beverages they consumed during each day of the past week, and how many alcoholic beverages they consumed normally on each day of a typical week.

\section{Procedure}

After giving consent, participants completed the AUDIT, performed the IAT, SRC and SST (in balanced order) and completed the TLFB. They were then assigned randomly to the beer/no-go condition $(n=27)$ or the beer/go condition $(n=30)$ and performed the go/no-go task. Immediately afterwards, participants again performed the IAT, SRC and SST (same counterbalancing as at pre-test). During the following week, participants completed a shortened version of the TLFB (i.e. not including average use for each day) on a daily basis. Upon returning the TLFB, participants received $€ 15$ or course credit as remuneration.

\section{RESULTS}

\section{Differences at pre-test}

Differences between the beer/go condition and the beer/ no-go condition on baseline variables, IAT scores and alcohol use were analysed using univariate analyses of variance (ANOVA), with condition as between-subjects factor. Approach RT, avoidance RT and SSRT were analysed using mixed ANOVAs with condition as betweensubjects factor and stimulus type (beer versus empty glasses) as within-subjects factor. Results showed no significant differences between conditions with respect to age, $F_{(1,55)}=0.93$, not significant (NS), AUDIT scores, $F_{(1,55)}=0.05$, NS or any of the dependent measures at pre-test: first, IAT scores did not differ significantly between the two conditions, $F_{(1,55)}=0.24$, NS. Secondly, approach and avoidance RT* also did not differ between conditions, $F_{(1,54)}=0.89$, NS and $F_{(1,54)}=0.73$, NS, respectively. The effect of stimulus type was significant, $F_{(1,54)}=5.36, \quad P=0.02$ and $F_{(1,54)}=8.20, \quad P=0.01$, respectively, indicating that participants were faster to both approach [Estimated Marginal Mean $(\mathrm{EMM})=558.02$, standard error $(\mathrm{SE})=16.79]$ and avoid beer $(\mathrm{EMM}=699.09, \mathrm{SE}=18.38)$ compared to empty glasses $(\mathrm{EMM}=594.46, \mathrm{SE}=16.97$ and $\mathrm{EMM}=769.07$, $\mathrm{SE}=26.64$, respectively). For both approach and avoidance RT, the interaction between stimulus type and condition was not significant, $F_{(1,54)}=0.24$, NS and

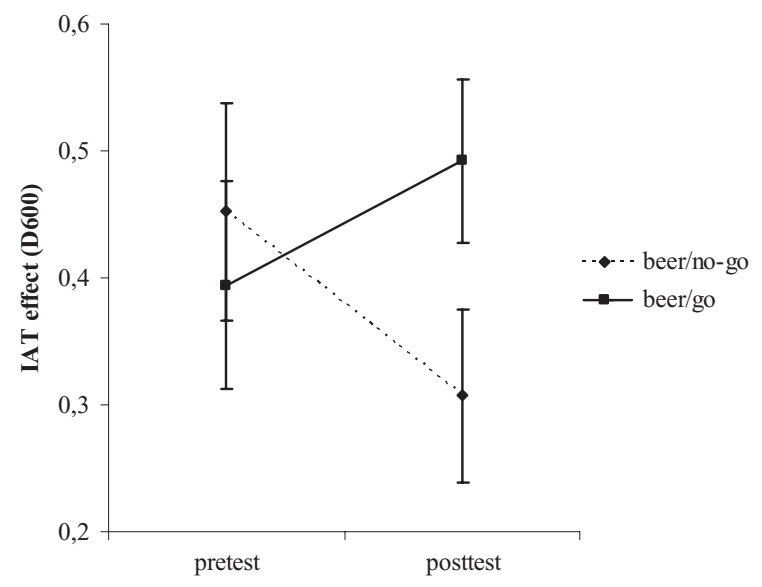

Figure I Mean Implicit Association Test (IAT) scores with standard errors at pre-test and post-test, separately for the beer/no-go condition and the beer/go condition. Higher IAT scores indicate stronger positive implicit attitudes towards beer

$F_{(1,54)}=0.00$, NS, respectively. Thirdly, the analyses on SSRT showed no significant effect of condition, $F_{(1,55)}=0.39$, NS, stimulus type, $F_{(1,55)}=0.00$, NS or interaction between condition and stimulus type, $F_{(1,55)}=0.35$, NS. Finally, there were no differences between conditions in alcohol use, $F_{(1,55)}=0.43$, NS.

\section{Go/no-go training}

The effect of the go/no-go manipulation on IAT scores, approach and avoidance RT and SSRT was examined using 2 (time: pre-test or post-test) $\times 2$ (condition: beer/ no-go or beer/go) mixed ANOVAs, with repeated measures on the first factor. ${ }^{\S}$ Stimulus type was added as a within-subjects factor in the analyses on approach RT, avoidance RT and SSRT.

With respect to IAT scores, results showed no significant effects of condition, $F_{(1,55)}=0.51$, NS or time, $F_{(1,55)}=0.21$, NS, while the expected time $\times$ condition interaction was significant, $F_{(1,55)}=5.56, \quad P=0.02$. Follow-up analyses showed a significant effect of time, $F_{(1,26)}=4.99, P=0.03$ in the beer/no-go condition, indicating that repeatedly pairing beer-related pictures with a no-go cue significantly decreased IAT scores so that participants were slower to associate beer with pleasant following the training (see Fig. 1). In the beer/go condition, the effect of time was not significant, $F_{(1,29)}=1.57$, NS.

With respect to approach $\mathrm{RT}, \ddagger$ results showed a significant effect of time, $F_{(1,54)}=17.63, \quad P<0.001$,

*ne participant did not complete the SRC at pre-test or at post-test, and therefore analyses on approach/avoidance RT were completed with only 56 participants ( $n=26$ in the beer/go condition and $n=29$ in the beer/no-go condition).

${ }^{\S}$ We performed sensitivity power analyses with G-power [27] to examine what effect size could be detected with a power of 0.80 , given the current sample size, and $\alpha=0.05$. These analyses showed that we were able to capture the crucial interaction effect between condition and time with a minimal effect size of $d=0.18$ for IAT scores, $d=0.24$ for approach RT, $d=0.24$ for avoidance RT, $d=0.12$ for stop-signal task performance and $d=0.17$ for alcohol use. We thus had enough statistical power to detect relatively small effects. 
demonstrating that participants were faster to approach both beer-related pictures and pictures of empty glasses at post-test $(\mathrm{EMM}=524.28, \mathrm{SE}=9.43)$ than at pre-test $(\mathrm{EMM}=576.24, \quad \mathrm{SE}=14.93)$. Further, the effect of stimulus type was significant, $F_{(1,54)}=13.22, P=0.001$, indicating that participants were faster to approach beerrelated pictures $(\mathrm{EMM}=533.26, \mathrm{SE}=10.90)$ than pictures of empty glasses $(\mathrm{EMM}=567.26, \mathrm{SE}=12.66)$. Neither the effect of condition, $F_{(1,54)}=0.37$, NS, nor any of the interaction terms were significant: time $\times$ condition, $F_{(1,54)}=1.48$, NS; type $\times$ condition, $F_{(1,54)}=$ 0.82 , NS; time $\times$ type, $F_{(1,54)}=0.06$, NS; time $\times$ type $\times$ condition, $F_{(1,54)}=0.01$, NS.

Similarly, the analysis on avoidance RT ${ }^{\ddagger}$ showed significant effects of time, $F_{(1,54)}=28.23, P<0.001$, and stimulus type, $F_{(1,54)}=12.30, P=0.001$, while neither the main effect of condition, $F_{(1,54)}=0.03$, NS, nor any of the interaction effects were significant: time $\times$ condition, $F_{(1,54)}=2.13$, NS; type $\times$ condition, $F_{(1,54)}=0.18$, NS; time $\times$ type, $F_{(1,54)}=1.83, \mathrm{NS}$; time $\times$ type $\times$ condition, $F_{(1,54)}=0.14$, NS. The significant main effects of time and stimulus type indicate that participants' avoidance responses became faster from pre-test $(\mathrm{EMM}=734.08$, $\mathrm{SE}=19.35)$ to post-test $(\mathrm{EMM}=629.97, \mathrm{SE}=13.90)$, and that participants were faster to avoid beer-related pictures $(\mathrm{EMM}=656.41, \mathrm{SE}=12.88)$ compared to pictures of empty glasses $(\mathrm{EMM}=707.64, \mathrm{SE}=17.79)$.

The analysis on SSRT showed no significant main effects of time, $F_{(1,55)}=2.89$, NS, stimulus type, $F_{(1,55)}=0.58$, NS or condition, $F_{(1,55)}=0.93$, NS. Further, no interaction effects reached significance, indicating that SST performance remained stable from pre-test to post-test in both conditions: time $\times$ condition, $F_{(1,55)}=1.55$, NS; type $\times$ condition, $F_{(1,55)}=1.56$, NS; time $\times$ type, $F_{(1,55)}=1.14, \mathrm{NS}$; time $\times$ type $\times$ condition, $F_{(1,55)}=0.28$, NS.

For alcohol use, results showed a significant interaction between time and condition, $F_{(1,54)}=5.43, P=0.02$, while the main effects of time and condition did not reach significance, $F_{(1,54)}=0.92$, NS and $F_{(1,54)}=0.19$, NS, respectively. "Follow-up analyses showed a significant effect of time in the beer/no-go condition, $F_{(1,25)}=6.86$, $P=0.02$, but no significant time effect in the beer/go condition, $F_{(1,29)}=0.82$, NS. As illustrated in Fig. 2, alcohol consumption decreased significantly from pretest to post-test in the beer/no-go condition, but showed a non-significant increase in the beer/go condition.**

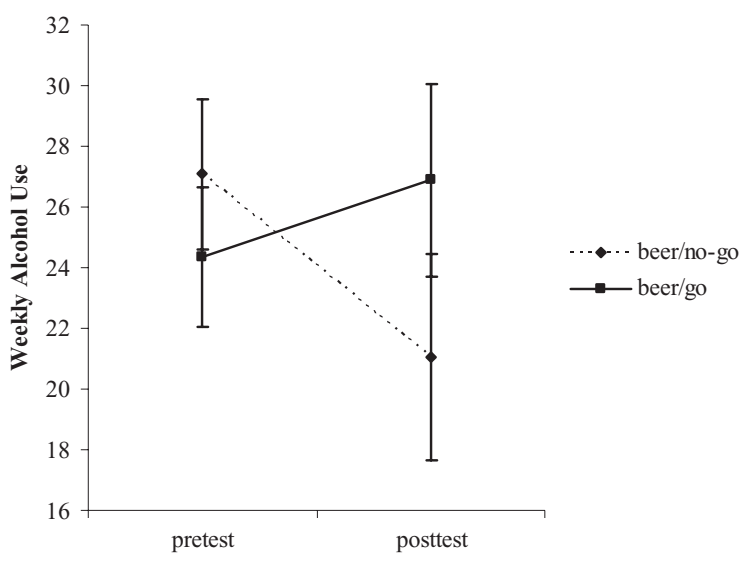

Figure 2 Weekly alcohol use with standard errors at pre-test and post-test, separately for the beer/no-go condition and the beer/go condition

\section{Mediation analysis}

Next, we tested whether training-induced changes in IAT scores, approach-avoidance RT and SSRT mediated the reduction in alcohol use from pre-test to post-test. Differences scores (pre-test-post-test) were calculated for all beer-related dependent variables. As shown in Table 1, condition predicted alcohol use change scores significantly. Further, condition also predicted IAT change scores significantly when controlling for the other potential mediators (approach/avoidance RT difference scores and SSRT difference scores). When alcohol use difference scores were regressed on IAT difference scores, approach and avoidance RT difference scores and SSRT difference scores, only IAT change scores significantly predicted changes in alcohol use. When condition was added to the model, condition no longer predicted alcohol change scores, while IAT change scores were marginally significant, suggesting that the effect of the go/no-go training on alcohol intake was mediated by training-induced changes in IAT scores.

\section{DISCUSSION}

As a direct replication of our previous findings [15], we again found that a go/no-go training that repeatedly pairs alcohol-related stimuli with a stopping response reduced alcohol intake. With respect to the possible mechanisms underlying this behavioural change, results showed that the training decreased positive

\footnotetext{
'One participant failed to hand in the second TLFB questionnaire, so analyses on weekly alcohol use were performed with only 56 participants ( $n=26$ in the beer/go condition and $n=29$ in the beer/no-go condition).

**We also calculated an estimate of mean alcohol use by averaging alcohol use during a typical week and alcohol use during the week prior to the manipulation. Re-analysing the data using this estimate in a 2 (time: mean alcohol use versus post-test alcohol use) $\times 2$ (condition: beer/no-go or beer/go) mixed analysis of variance yielded exactly the same pattern of results, suggesting that regression to the mean was not responsible for the present findings.
} 
Table 1 Unstandardized regression coefficients for the mediation analyses for the indirect effects of go/no-go training on alcohol use.

\begin{tabular}{|c|c|c|c|c|}
\hline & \multicolumn{4}{|c|}{ Model 1} \\
\hline & $B$ & $S E$ & $T$ & $P$ \\
\hline \multirow[t]{3}{*}{ Condition } & -8.56 & 3.67 & -2.33 & 0.02 \\
\hline & \multicolumn{4}{|c|}{ Model 2} \\
\hline & $B$ & $S E$ & $T$ & $P$ \\
\hline Condition & -0.28 & 0.11 & -2.62 & 0.01 \\
\hline Approach RT change & 0.00 & 0.00 & -0.91 & 0.36 \\
\hline Avoidance RT change & 0.00 & 0.00 & 1.54 & 0.13 \\
\hline \multirow[t]{3}{*}{ SSRT change } & 0.00 & 0.00 & 0.70 & 0.49 \\
\hline & \multicolumn{4}{|c|}{ Model 3} \\
\hline & $B$ & $S E$ & $T$ & $P$ \\
\hline IAT change & 11.61 & 4.73 & 2.46 & 0.02 \\
\hline Approach RT change & 0.01 & 0.01 & 0.65 & 0.52 \\
\hline Avoidance RT change & -0.02 & 0.01 & -1.23 & 0.22 \\
\hline \multirow[t]{3}{*}{ SSRT change } & -0.07 & 0.04 & -1.59 & 0.12 \\
\hline & \multicolumn{4}{|c|}{ Model 4} \\
\hline & $B$ & $S E$ & $T$ & $P$ \\
\hline IAT change & 9.62 & 4.96 & 1.94 & 0.06 \\
\hline Approach RT change & 0.01 & 0.01 & 0.45 & 0.65 \\
\hline Avoidance RT change & -0.01 & 0.01 & -0.87 & 0.39 \\
\hline SSRT change & -0.06 & 0.04 & 1.36 & 0.18 \\
\hline Condition & -5.11 & 4.05 & -1.26 & 0.21 \\
\hline
\end{tabular}

Model 1 specifies the regression coefficients for the regression of alcohol use change scores on condition. Model 2 specifies the regression coefficients for the regression of Implicit Association Test (IAT) change scores on condition, when controlling for approach reaction time (RT) change scores, avoidance RT change scores and stop-signal reaction time (SSRT) change scores. Model 3 specifies the regression coefficients for the regression of alcohol use change scores on IAT change scores, approachavoidance RT change scores and SSRT change scores. Model 4 specifies the regression coefficients for the regression of alcohol use change scores on IAT change scores, approach-avoidance RT change scores, SSRT change scores and condition. SE: standard error.

implicit attitudes towards alcohol. However, we found no training effects on action tendencies or response inhibition. Consistent with these findings, previous research also showed similar devaluation effects following go/no-go training $[15,16]$.

According to the BSI theory by Veling et al. [16], the observed devaluation occurs because the approach tendency elicited by positive stimuli needs to be inhibited when approach is unwanted (e.g. due to a no-go signal) [16]. Consequently, a positive stimulus that first prompted a behavioural approach tendency will stop doing so, thereby also reducing its positive value. While the present findings indeed support the devaluation hypothesis, we found no support for reduced approach tendencies following the training. The present findings therefore suggest that the devaluation of alcohol-related stimuli coincided with newly learned associations between alcohol and not responding, rather than a change in existing alcohol associations with approachavoidance. In this sense, the training might operate in the same way as extinction learning: exposure to the conditioned stimulus (CS; e.g. alcohol cues) without the unconditioned stimulus (US; e.g. approach behaviour) does not destroy the existing CS-US association, but causes a newly learned inhibitory CS-US association $[28,29]$.

Consistent with this view, Verbruggen \& Logan proposed that pairing stimuli consistently with no-go signals causes participants to learn new associations between these stimuli and stopping [18]. Importantly, such automatic stimulus-stop associations suppress go responses and facilitate automatic inhibition, thereby reducing the need for top-down executive control. This can also explain why we failed to find effects of the go/no-go training on response inhibition as measured with the SST. Specifically, Verbruggen \& Logan propose that the go/no-go task may be more sensitive to automatic, bottom-up inhibition processes while the SST more probably taps controlled, top-down inhibition processes [18]. Hence, it is possible that the present go/no-go training increased automatic associations between alcoholrelated stimuli and stopping, but did not induce changes in the higher-order executive control system that is needed to control actions intentionally.

To resolve this issue further, future research should examine whether go/no-go training indeed induces automatic associations with stopping. However, it should also be noted that, even though a power analysis showed that we were able to detect relatively small effects, the possibility remains that our power was still insufficient to detect effects of the go/no-go training on approach-avoidance motivation and/or inhibitory control as measured with the SST. Moreover, it is also possible that the training induced changes in top-down inhibitory control but that the SST was not sensitive enough to tap such traininginduced changes. Therefore, future research should also include other measures of inhibitory control to examine this issue further.

Importantly, as in our previous study, pairing stopping responses consistently with alcohol cues reduced alcohol intake. Further, this reduction in drinking was mediated by changes in implicit attitudes rather than by changes in approach-avoidance motivations or (controlled) response inhibition. Hence, the go/no-go training resembles evaluative conditioning [12,13] more than executive control training [14]. Specifically, 
go/no-go training seems to reduce alcohol intake via a decrease in affective associations in the impulsive system, rather than by strengthening executive control over such automatic impulses. However, implicit attitude changes significantly mediated the reduction in alcohol intake only marginally, suggesting that other processes such as automatic stopping associations may have contributed to the observed change in drinking. Therefore, future research should examine whether the training indeed induces stopping associations with alcohol and how these associations mediate changes in drinking behaviour.

In conclusion, in two studies we have now demonstrated that the consistent mapping of alcohol-stimuli onto a stopping response during a go/no-go training reduces alcohol intake. Importantly, this reduction does not appear to be mediated by a general strengthening of inhibitory control ability, but rather by changing implicit attitudes towards alcohol-related stimuli and/or an increase of automatic associations between alcohol and not responding.

\section{Declarations of interest}

None.

\section{Acknowledgements}

This research was supported by a grant from ERAB: the European Foundation for Alcohol Research, awarded to the first author.

\section{References}

1. Bechara A., Noel X., Crone E. A. Loss of willpower: abnormal neural mechanisms of impulse control and decision making in addiction. In: Wiers R. W., Stacy A. W., editors. Handbook of Implicit Cognition and Addiction. Thousand Oaks, CA: Sage Publishers; 2006, p. 215-32.

2. Deutsch R., Strack F. Reflective and impulsive determinants of addictive behavior. In: Wiers R. W., Stacy A. W., editors. Handbook of Implicit Cognition and Addiction. Thousand Oaks, CA: Sage Publishers; 2006, p. 45-57.

3. Wiers R. W., Bartholow B. D., van den Wildenberg E., Thush C., Engels R. C. M. E., Sher K. J. et al. Automatic and controlled processes and the development of addictive behaviors in adolescents: a review and a model. Pharmacol Biochem Behav 2007; 86: 263-83.

4. Houben K., Wiers R. W. Are drinkers implicitly positive about drinking alcohol? Personalizing the alcohol-IAT to reduce negative extrapersonal contamination. Alcohol Alcohol 2007; 42: 301-7.

5. Houben K., Wiers R. W. Personalizing the alcohol-IAT with individualized stimuli: relationship with drinking behavior and drinking-related problems. Addict Behav 2007; 32: 2852-64.

6. Houben K., Wiers R. W. Implicitly positive about alcohol? Implicit positive associations predict drinking behavior. Addict Behav 2008; 33: 979-86.
7. Jajodia A., Earleywine M. Measuring alcohol expectancies with the implicit association test. Psychol Addict Behav 2003; 17: 126-33.

8. McCarthy D. M., Thompsen D. M. Implicit and explicit measures of alcohol and smoking cognitions. Psychol Addict Behav 2006; 20: 436-44.

9. Grenard J. L., Ames S. L., Wiers R. W., Thush C., Sussman S., Stacy A. W. Working memory moderates the predictive effects of drug-related associations on substance use. Psychol Addict Behav 2008; 22: 426-32.

10. Houben K., Wiers R. W. Response inhibition moderates the influence of implicit associations on drinking behavior. Alcohol Clin Exp Res 2009; 33: 626-33.

11. Thush C., Wiers R. W., Ames S. L., Grenard J. L., Stacy A. W. The interaction between working memory and implicit alcohol-related cognition in the prediction of prospective drinking in at-risk youth. Paper presented at the Third NWO Cognition Summer School, Doorwerth, the Netherlands, 13-15 October; 2006.

12. Houben K., Havermans R. C., Wiers R. W. Learning to dislike alcohol: conditioning negative implicit attitudes towards alcohol and its effects on drinking behavior. Psychopharmacology (Berl) 2010; 211: 79-86.

13. Houben K., Schoenmakers T., Wiers R. W. I didn't feel like drinking but I don't know why: the effects of evaluative conditioning on alcohol-related attitudes, craving and behavior. Addict Behav 2010; 35: 1161-3.

14. Houben K., Wiers R. W., Jansen A. Getting a grip on drinking behavior: training working memory to reduce alcohol abuse. Psychol Sci 2011; 22: 968-75.

15. Houben K., Nederkoorn C., Wiers R. W., Jansen A. Resisting temptation: decreasing alcohol-related affect and drinking behavior by training response inhibition. Drug Alcohol Depend 2011; 116: 132-6.

16. Veling H., Holland R. W., van Knippenberg A. When approach motivation and behavioral inhibition collide: behavior regulation through stimulus devaluation. J Exp Soc Psychol 2008; 44: 1013-9.

17. Veling H., Aarts H. Unintentional preparation of motor impulse after incidental perception of need-rewarding objects. Cogn Emot 2011; 25: 1131-8.

18. Verbruggen F., Logan G. D. Automatic and controlled response inhibition: associative learning in the Go/No-Go and Stop-Signal paradigms. J Exp Psychol Gen 2008; 137: 649-72.

19. Saunders J. B., Aasland O. G., Babor T. F., De la Fuente J. R., Grant M. Development of the Alcohol use Disorders Identification Test (AUDIT): WHO collaborative project on early detection of persons with harmful alcohol consumption. Addiction 1993; 88: 791-804.

20. Greenwald A. G., McGhee D. E., Schwartz J. L. K. Measuring individual differences in implicit cognition: the implicit association test. J Pers Soc Psychol 1998; 74: 1464-80.

21. Greenwald A. G., Nosek B. A., Banaji M. R. Understanding and using the implicit association test: I. An improved scoring algorithm. J Pers Soc Psychol 2003; 85: 197-216.

22. Krieglmeyer R., Deutsch R., De Houwer J., De Raedt R. Being moved: valence activates approach-avoidance behavior independently of evaluation and approach avoidance intentions. Psychol Sci 2010; 21: 607-13.

23. Logan G. D., Schachar R. J., Tannock R. Impulsivity and inhibitory control. Psychol Sci 1997; 8: 60-4.

24. Scheres A., Oosterlaan J., Swanson J., Morein-Zamir S., Meiran N., Schut H. et al. The effect of methylphenidate on 
three forms of response inhibition in boys with $\mathrm{AD} / \mathrm{HD}$. J Abnorm Child Psychol 2003; 31: 105-20.

25. Wiers R. W., Hoogeveen K.-J., Sergeant J. A., Gunning W. B. High- and low-dose alcohol-related expectancies and the differential associations with drinking in male and female adolescents and young adults. Addiction 1997; 92: 871-88.

26. Sobell L. C., Sobell M. B. Self-report issues in alcohol abuse: state of the art and future directions. Behav Assess 1990; 12: 77-90.
27. Faul F., Erdfelder E., Lang A.-G., Buchner A. G*Power 3: a flexible statistical power analysis program for the social, behavioral, and biomedical sciences. Behav Res Methods 2007; 39: 175-91.

28. Bouton M. E. Context, ambiguity, and classical conditioning. Curr Dir Psychol Sci 1994; 3: 49-53.

29. Havermans R. C., Jansen A. Increasing the efficacy of cue exposure treatment in preventing relapse of addictive behavior. Addict Behav 2003; 28: 989-94. 